\title{
Thermal Simulation of Power Lithium-ion Battery Module
}

\author{
*Fancong Zeng ${ }^{1}$, Zhijiang Zuo ${ }^{1}$, Han $\mathrm{Li}^{1}$ and Libo $\mathrm{Pan}^{1}$ \\ ${ }^{1}$ School of Intelligent Manufacturing, Jianghan University, Hubei Wuhan 430056, China
}

\begin{abstract}
Thermal management of power lithium-ion battery modules is very important to avoid thermal problems such as overheating and out of control, the study of thermal behavior of battery modules can provide guidance for the design and optimization of modules and thermal management. In this paper, a $3 \mathrm{~d}$ thermal model of the power lithium-ion battery module is established based on STARCCM+ by using computational fluid dynamics (CFD) method, and a grid independence simulation test is used to determine the number of grids, the temperature distribution is analyzed under the condition of $1 \mathrm{C}$ charge current. The research results show that the internal temperature rises gradually with the charge going on, the temperature distribution of the cells is basically symmetrical. When the heat transfer coefficient is $5 \mathrm{~W} /\left(\mathrm{m}^{2} \cdot \mathrm{K}\right)$ and the natural convective air inlet temperature is $300 \mathrm{~K}$, the module temperature uniformity is good. But because of the maximum temperature slightly higher than the temperature of thermal runaway, additional cooling methods need to be considered to cool the battery.
\end{abstract}

\section{Introduction}

Lithium-ion battery has been widely used due to its high energy density, high nominal voltage, low self-discharge rate, long cycle life and other advantages. In order to prolong the service life of lithium-ion batteries, the phenomena of over voltage, over current or power limit and thermal runaway should be avoided in the process of discharging and charging. The internal temperature rise is more obvious when a battery pack in a confined space is charged and discharged with a large current for a long time. When the temperature exceeds a certain limit, the battery may be in danger of expansion, leakage, and even explosion. Temperature is an important factor affecting the thermoelectric chemical performance, final performance and cycle life of lithium-ion batteries[1].

The evaluation of temperature standard deviation of power lithium-ion module should be reflected by evaluating its temperature distribution and temperature consistency. With the rapid development of Computational Fluid Dynamics (CFD) and computer technology, the application of various CFD softwares has become more efficient and mature. The application of CFD technology to model the thermal field of power lithium-ion module has been able to effectively shorten the design cycle and save costs. Yuan et al[2] applied CFD method to study the influence of air inlet velocity, air inlet angle and battery spacing on the heat dissipation of lithium-ion battery pack, and carried out optimization analysis. Yin et al[3] established a three dimensional thermal model of lithium-ion battery based on COMSOL simulation platform and quantitatively analyzed the temperature distribution under $5 \mathrm{C}$ operating current. Luo et al[4] used COMSOL Multiphysics simulation software to conduct simulation analysis on the temperature field of lithium-ion battery unit and battery pack under different charging rates, and verified the accuracy of the model through experiments. Battery cooling system were analyzed by Zhao et al to get the main factors influencing the battery temperature, a kind of fuzzy PID temperature control algorithm was put forward. The battery thermal management system strategy was designed in combination with the target of the battery thermal management system, and the bench thermal balance test was carried out for the battery with the temperature control strategy, and then the vehicle high temperature test was carried out[5]. Pan et al[6] tested the urban circulation condition of the experimental lithium-ion battery and obtained its surface temperature data and bus current data. On this basis, the material characteristic parameters of the battery were analyzed and calculated, and the heat dissipation model of the power battery was established and then the model was simulated.

Based on STARCCM+ numerical simulation software, this paper establishes a three dimensional model of the single module of a domestic lithium-ion battery model, studies the temperature distribution of the battery module under charging condition of $1 \mathrm{C}$ rate at normal temperature, and provides guidance for the design and optimization of the module and thermal management.

\section{Heat flow model based on CFD}

The lithium-ion battery module is placed in the box and conducts natural convection heat transfer with the surrounding air. The three dimensional model of the lithium-ion battery module is shown in Figure 1. The

Corresponding author: zengfancong2018@163.com 
simulation process is set as continuous charging of $1400 \mathrm{~s}$ at an initial temperature of $300 \mathrm{~K}$ and $1 \mathrm{C}$ charging rate. In this process, the heat source (lithium-ion battery module) is defined using a user-defined field function. Because of the anisotropy of the conductivity inside the battery, the temperature of the entire cross section of the battery can be calculated by defining the battery as a heat source rather than a heat flow boundary on the surface. Compared with heat conduction, the effect of heat radiation in simulation can be ignored. STARCCM+ software is used for grid division and numerical calculation. The boundary of the lithium-ion battery module is defined as convective heat transfer boundary, the heat transfer coefficient is set to $5 \mathrm{~W} /(\mathrm{m} 2 \cdot \mathrm{K})$, and the natural convective air inlet temperature is set to ambient temperature $300 \mathrm{~K}$.

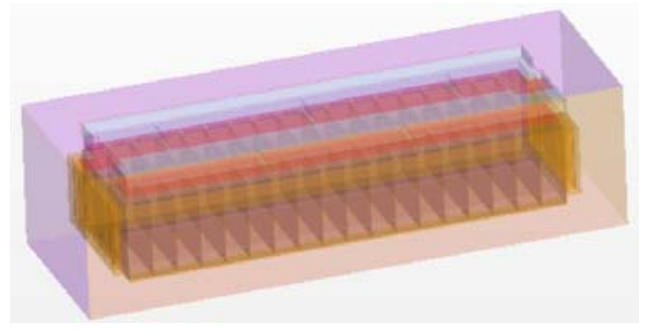

Figure 1. 3D model of lithium-ion battery module

Figure 2 is a grid independence test considering the temperature at the same point of the cell, which can be used to ensure the reliability of subsequent simulation and optimization[7]. As shown in the figure, when the total number of grids remains above about 830000 , the results can remain within a stable range. Therefore, in order to save calculation cost, the grid number is defined as 835904 , and the grid model is shown in Figure 3.

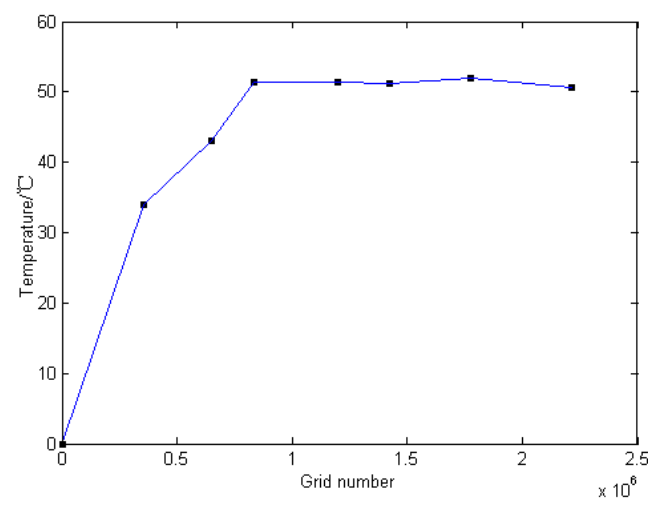

Figure 2. Grid independence test considering the maximum surface temperature of intermediate cell

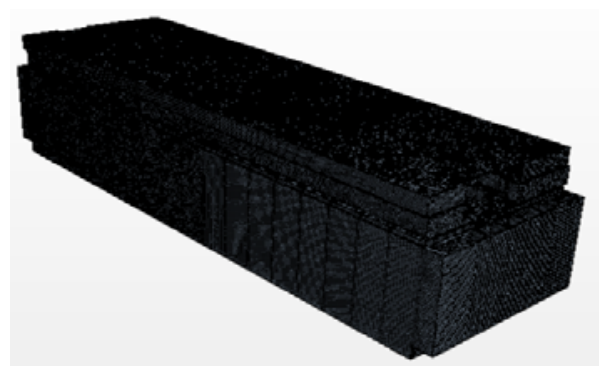

Figure 3. Grid model of lithium battery module
In order to facilitate the analysis of flow field and thermal response, the following assumptions are made[8]:

(1) air flow is laminar flow;

(2) Incompressible flow;

(3) Ignore gravity;

(4) Ignore the heat radiation between the cells;

(5) Uniform heat generation;

(6) Current density distribution within the battery.

In order to obtain the temperature distribution of lithium-ion battery modules, the conservation equation of heat conduction energy can be expressed as[9]:

$$
\rho \mathrm{c}_{p} \frac{\partial T}{\partial \tau}=\frac{\partial}{\partial x}\left(k_{x} \frac{\partial T}{\partial x}\right)+\frac{\partial}{\partial y}\left(k_{y} \frac{\partial T}{\partial y}\right)+\frac{\partial}{\partial z}\left(k_{z} \frac{\partial T}{\partial z}\right)+Q_{v}
$$

Where $\rho$ is density of the battery; $c p$ is specific heat capacity of the battery; kx, ky, kz are thermal conductivity along the direction of $\mathrm{x}, \mathrm{y}$ and $\mathrm{z}$ respectively; $\mathrm{T}$ is temperature of the battery; $\tau$ is battery charging time; $\mathrm{Qv}$ is volume heat source in the cell, generated by the electrochemical enthalpy change and internal thermal resistance, Qv is shown in formula (2).

$$
Q_{v}=I\left(U_{O C}-V\right)-I T \frac{d U_{O C}}{d T}
$$

Where I is current of the battery; UOC is open circuit voltage of the battery; $\mathrm{V}$ is operating voltage of the battery; dUOC/dT is derivative of the equilibrium potential temperature of the battery.

According to Newton's cooling law, the boundary conditions of the battery heat flow model can be expressed as:

$$
-\lambda\left(\frac{\partial T}{\partial n}\right)=h\left(T_{a m b}-T_{\infty}\right)
$$

Where $\lambda$ is thermal conductivity of the surface material of the battery; $n$ is vector direction perpendicular to the battery surface; $h$ is convective heat transfer coefficient between the cell surface and surrounding fluids; Tamb is ambient fluid temperature; T $\infty$ is battery surface temperature.

\section{Simulation results and analysis}

\subsection{Simulation results}

To study the thermal response of the entire battery module, the overall temperature distribution should be investigated firstly. Figure 4 shows the temperature distribution of the battery module and Figure 5 shows the temperature distribution of the cell. It can be seen from the figure that the cell temperature distribution of the battery module is basically symmetrical. The temperatures in the middle of the side panel and the cell of the battery module are the highest, while the temperature at both sides and corners is slightly lower. Because the heat dissipation condition of the central position is worse than that of the two sides and corners, and the insulation film of the upper part of the battery is basically in the state of heat insulation, basically will not transfer the heating heat of the module to the outside of the battery. In addition, the temperature of the bottom surface of the module is higher than that of the top surface, because the thermal conductivity of the bottom 
cell is higher than that of the upper cover plate, integrated cover plate, insulation film, thermal conductive adhesive and other components. Moreover, the top of the module is not completely in contact with the cover plate, and there is an air layer with a certain space, so the heat transfer effect is poor.

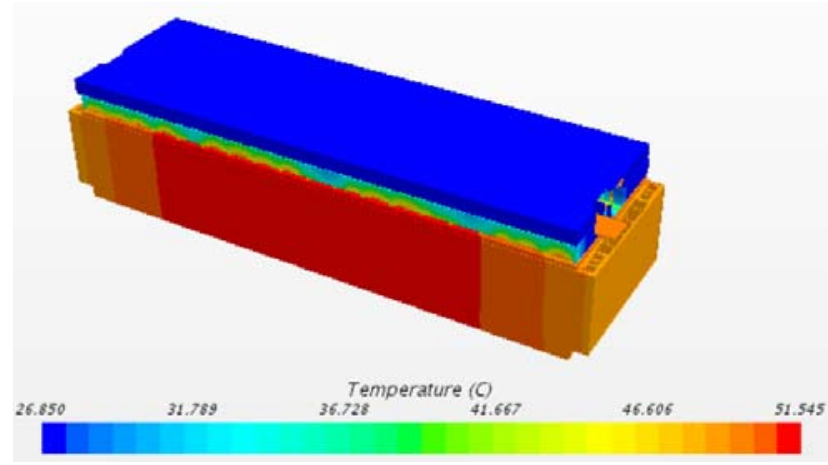

Figure 4. Temperature chart of lithium-ion battery module

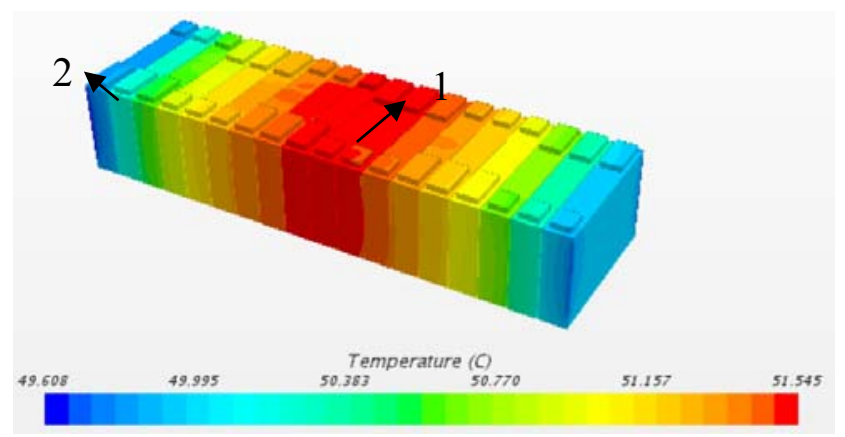

Figure 5. Temperature chart of battery cell

In order to observe the temperature distribution inside the lithium-ion battery cell more clearly, the section temperature is selected for observation, as shown in Figure 6. The temperature of the cell is distributed in a radial manner. Among them, the temperature of the middle cell is high, and the temperature of the cells on both sides is low. The temperature of the same cell is consistent all over the section, and the temperature inside the cell is consistent. The temperature distribution of different cells has a large temperature gradient, and the maximum temperature difference is about $2^{\circ} \mathrm{C}$.

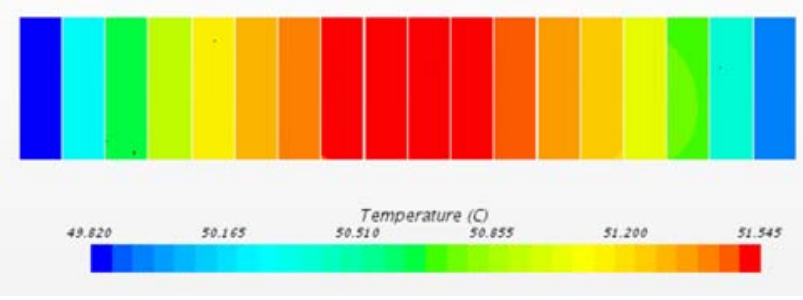

Figure 6. Temperature of battery cell in the same section

\subsection{Module temperature distribution}

The battery charging is transient, and the temperature probe is used to monitor the local temperature of some points and detect the temperature change of a certain point of the battery with time. Figure 7 shows the battery temperature change curves of the two monitoring points ( 1 and 2 in Figure 5) of the upper end face cell and the intermediate cell of the module. It can be seen that the battery temperature shows a trend of gradual increase with charging time. After charging, the temperature of monitoring point 1 is $50.68^{\circ} \mathrm{C}$, and temperature of monitoring point 2 is $48.68^{\circ} \mathrm{C}$, which is about higher than the temperature of thermal runaway (about $45^{\circ} \mathrm{C}$ ). Because the cooling system is not added in this simulation, indicating that the heat of the battery pack is too high under $1 \mathrm{C}$ charging, so the cooling system is needed to solve the problem of thermal runaway.

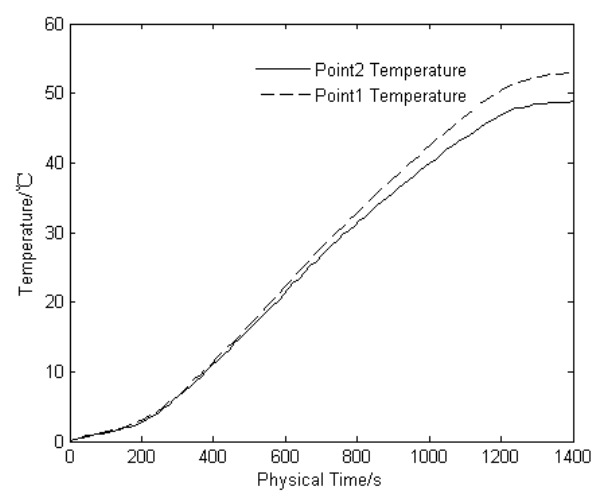

Figure 7. The relationship between the temperature of monitoring points and charging time

In general, the normal operating temperature range of power lithium-ion batteries is $-20^{\circ} \mathrm{C} \sim 50^{\circ} \mathrm{C}$, generally lower than $0^{\circ} \mathrm{C}$ and higher than $50^{\circ} \mathrm{C}$ battery performance will decline, the ability to charge and discharge will be reduced. Therefore, the working temperature to ensure good performance of power lithium-ion battery is generally $0 \sim 45^{\circ} \mathrm{C}$, and the maximum temperature difference within the module should not exceed $5^{\circ} \mathrm{C}$.

Figure 8 shows the curves of maximum temperature and minimum temperature changing with time in the module under $1 \mathrm{C}$ charging condition. It can be seen from the figure that the maximum temperature in the module after charging is $51.41^{\circ} \mathrm{C}$, the minimum temperature is $49.16^{\circ} \mathrm{C}$, and the maximum temperature difference is $2.25^{\circ} \mathrm{C}$, which meets the requirement of temperature consistency in the lithium-ion battery module.

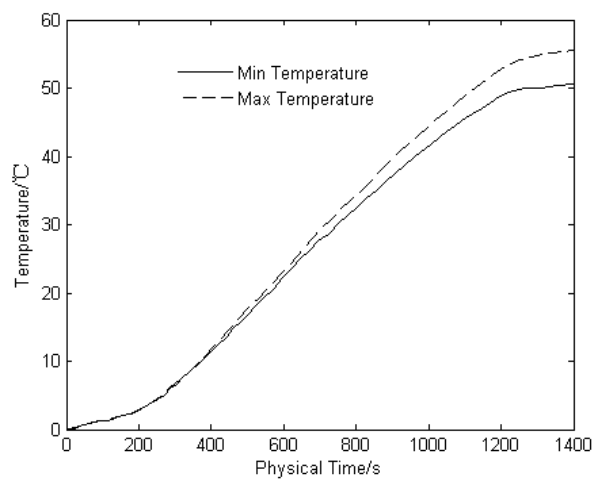

Figure 8. The relationship between the maximum temperature, minimum temperature and charging time 


\section{Conclusion}

In this paper, a single module of a domestic lithium-ion battery model is taken as the research object, and a three dimensional model of the lithium-ion battery module under closed conditions is established. Based on the STARCCM+ numerical simulation platform, the thermal behavior of the battery module under charging condition of $1 \mathrm{C}$ rate at normal temperature is studied based on the CFD technology. The following conclusions can be drawn:

(1) The temperature distribution of the cell in the battery module is basically symmetrical. The temperature of the cell in the middle part of the battery module is the highest, while the temperature of both sides and corners is slightly lower;

(2) With a heat transfer coefficient of $5 \mathrm{~W} /(\mathrm{m} 2 \cdot \mathrm{K})$, a natural convective air inlet temperature of $300 \mathrm{~K}$ and a $1 \mathrm{C}$ charging rate of $1400 \mathrm{~S}$, the maximum temperature of the battery module cell reaches $51.41{ }^{\circ} \mathrm{C}$, higher than the heat control temperature. At this point, additional heat dissipation methods should be considered to cool the battery;

(3) There is a certain temperature gradient inside the single module, and the module has a good temperature consistency. The difference between the highest temperature and the lowest temperature is $2.25^{\circ} \mathrm{C}$.

\section{References}

1. S.Q. Chen, X.B. Peng, N.S. Bao, A. Rarg, Appl. Therm. Eng. 156 (2019)

2. Z. Yuan, J. Zhao, L. Han, Batt. Bimon. 49, 3 (2019)

3. B.H. Yin, L. Ai, Z.A. Yang, Pow. Sup. Tech. 41, 5 (2019)

4. W.L. Luo, S.Y. Zhou, H. Liu, Equ. Envir. Eng. 15, 12 (2018)

5. L. Zhao, J.X. Zhu, A.H. Chu, Mach. Des. and Manu. 9 (2020)

6. C.F. Pan, G.Q. Li, L. Chen, Mach. Des. and Manu. 9 (2017)

7. T. Deng, Y. Ran, Y.L. Yin, X. Chen, P. Liu, Int. J. Heat. Mass. Tran. 143 (2019)

8. R.C. Adhikari, D.H. Wood, M. Pahlevani, Ther. Sci. and Eng. Pro. 17 (2020)

9. A. Tang, J.M. Li, L.S. Lou, C.X. Shan, X.Z. Yuan, Appl. Therm. Eng. 159 (2019) 